\title{
Practices to Preserve Human Competencies and Their Impact on Achieving Institutional Excellence in the Social Security Institution Jordan
}

\author{
Mahmoud Hussein Abu Joma, Sanaa Mohammad Khames Alderbashi
}

To Link this Article: http://dx.doi.org/10.6007/IJARBSS/v11-i9/11248

DOI:10.6007/IJARBSS/v11-i9/11248

Received: 11 July 2021, Revised: 08 August 2021, Accepted: 28 August 2021

Published Online: 23 September 2021

In-Text Citation: (Joma \& Alderbashi, 2021)

To Cite this Article: Joma, M. H. A., \& Alderbashi, S. M. K. (2021). Practices to Preserve Human Competencies and Their Impact on Achieving Institutional Excellence in the Social Security Institution Jordan. International Journal of Academic Research in Business and Social Sciences, 11(9), 1702-1724.

Copyright: (c) 2021 The Author(s)

Published by Human Resource Management Academic Research Society (www.hrmars.com)

This article is published under the Creative Commons Attribution (CC BY 4.0) license. Anyone may reproduce, distribute, translate and create derivative works of this article (for both commercial and non-commercial purposes), subject to full attribution to the original publication and authors. The full terms of this license may be seen

at: http://creativecommons.org/licences/by/4.0/legalcode

Vol. 11, No. 9, 2021, Pg. 1702 - 1724

Full Terms \& Conditions of access and use can be found at http://hrmars.com/index.php/pages/detail/publication-ethics 


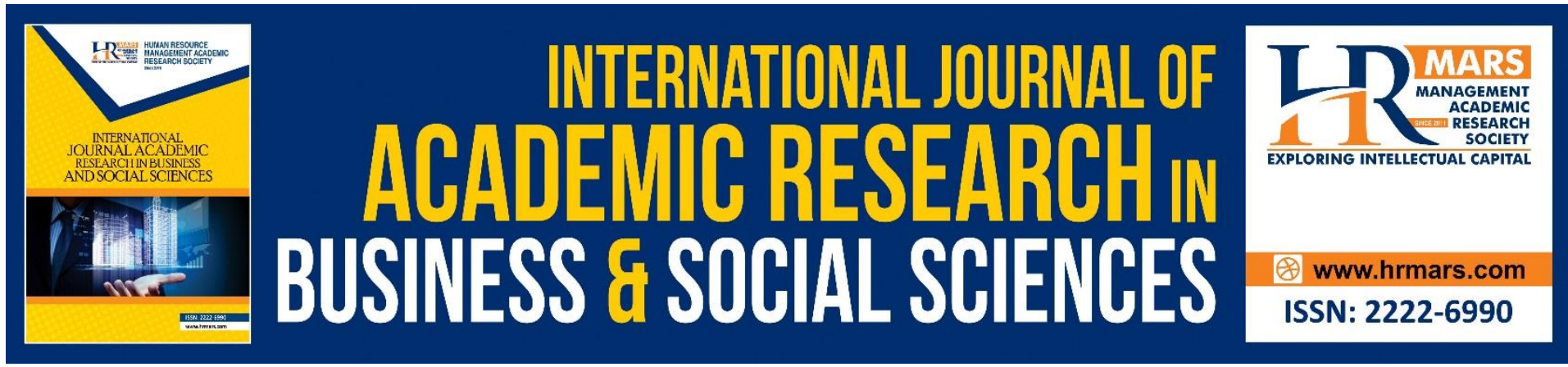

\title{
Practices to Preserve Human Competencies and Their Impact on Achieving Institutional Excellence in the Social Security Institution Jordan
}

\author{
Dr. Mahmoud Hussein Abu Joma \\ Amman Arab University - Faculty of Business
}

\author{
Mrs. Sanaa "Mohammad Khames" Alderbashi \\ Amman Arab University - HR Management Branch
}

\begin{abstract}
The importance of the study comes from the need to identify human competencies and their impact on institutional excellence, and this study derives its importance through its useful contributions, both theoretical and practical. This study relied on the descriptive analytical approach to test the impact of human competency practices with their dimensions on institutional excellence in its dimensions by reviewing relevant previous studies, and using the questionnaire as a tool for data collection that will cover the results of the analysis of the practical side of the study. To answer the study questions and test the hypotheses, the data will be processed using the Statistical Package for the Social Sciences: SPSS, where the following statistical analyzes were used:

.1.Frequencies and percentages to describe the demographic and functional characteristics of the study sample members.

.Arithmetic averages and standard deviations of the study tool items and areas. 2

.Cronbach Alpha internal consistency coefficient to verify the stability of the study tool. 3

4. Multiple regression analysis in order to measure the effect of the dimensions of the independent variables on one dependent variable.

This study aimed to demonstrate the impact of the practices of maintaining human competencies and their impact on achieving institutional excellence in the Jordanian Social Security Corporation, through the statement of the impact of human competency practices in their dimensions (competence, knowledge, good behavior, skills) on leadership excellence in the Social Security Corporation, and a statement the impact of human competency practices with their dimensions (efficiency, knowledge, good behavior, skills) on excellence in service provision in the Social Security Corporation. The study used the analytical descriptive method. The study sample consisted of (141) male and female employees of the Social Security Institution, regardless of administrative level, age, or gender. The results of the study showed that there is an impact of human competencies with their dimensions (efficiency, knowledge, good behavior, skills) in institutional excellence in its dimensions (leadership excellence, excellence in the service provided) in the Social Security Institution, as well as there is an impact of human competencies in its dimensions (efficiency, knowledge, good
\end{abstract}


behavior, Skills) in excellence in the service provided in the Social Security Institution. The results of the summary of the model to test the main hypothesis showed that the value of the correlation coefficient between the independent variable (human competency practices) and the dependent variable (institutional excellence) together amounted to (.749), which indicates the existence of a medium positive correlation between the variables, and the table also shows that The value of the coefficient of determination (R2) (.561), meaning that the model explained the proportion of $(56.1 \%)$ of the total variance of the dependent variable (institutional excellence), while the rest is explained by other factors. Based on the results of the analysis of the hypotheses of the study, the researchers reached in this study, the researchers recommended that it is necessary that one of the organization's strategic goals should be concerned with adopting, encouraging, and maintaining the competencies of its employees for the purpose of achieving institutional excellence so we recommended this and also recommended working on holding continuous courses to raise skills, knowledge, and competences of employees, which increase their loyalty and raise the level of performance, which also increases the process of excellence.

Keywords: Human Competencies, Institutional Excellence, Leadership Excellence, Social Security Institution.

\section{The General Framework of the Study}

Human competencies are considered one of the most important components on which organizations are based in general, and they are the cornerstone on which organizations are built. As the higher competencies the organizations have, the more these organizations tend to differentiate between the organizations, whether these organizations are in the same competing sector or even in other sectors.

Human resource management plays an influential role in meeting the requirements of achieving excellence, which made human resource management of special importance and vitality that changed its nature and operations. The development of information technology has increased the demand for technical professions that require non-traditional qualifications for leadership positions in information management. And the necessity of introducing modern technology and relying on it in the activities and tasks of human resources management, including planning, attraction, selection, and appointment (Madani, 2015).

In light of the foregoing, the main role played by human resources departments in all organizations, including the General Organization for Social Security, is to provide the necessary, effective and specialized manpower, in addition to carrying out many tasks and responsibilities such as planning, recruitment and training. Thus, the current study seeks to identify the practices of maintaining human competencies in achieving institutional excellence in the social security public institution.

\section{Research Problem}

Human competencies contribute significantly to the improvement of management systems in general, when the management problems facing organizations are exacerbated, and the fact that the strategic direction of human competencies is to make long-term decisions about the organization's employees at all organizational levels. Which expresses the general orientation of the organization to achieve its strategic (long-term) goals and achieve excellence through its human competencies that contribute to its efforts in organizing the organization's work and activities (Manal, 2015).

Based on the aforementioned and what was recommended by a number of relevant previous 
studies, such as the Najwa study (2020) and the Tawfiq study (2019), about conducting further studies in this regard, and because one of the researchers works in the Social Security Institution, the two researchers agreed to conduct this study, which can Show its problem more clearly by raising the following main question: Is there an impact of the practices of human competencies in achieving institutional excellence in the social security public institution?.

\section{Research Questions}

The study questions were developed based on the identified gaps in the current body of knowledge as follows:

The main question: Is there an impact of the practices of human competencies with their dimensions (efficiency, knowledge, good behavior, skills) on institutional excellence in its dimensions (leadership excellence, service excellence) in the Public Institution for Social Security? And branch out from the main question two sub-questions that we will address when presenting the hypotheses.

\section{Research Objectives}

This study aims to demonstrate the impact of the practices of maintaining human competencies and their impact on achieving institutional excellence, where the following objectives can be stated from the main objective:

1-Statement of the impact of human competency practices with their dimensions (efficiency, knowledge, good behavior, skills) on leadership excellence in the social security public institution.

2-Statement of the impact of human competencies practices with their dimensions (efficiency, knowledge, good behavior, skills) on excellence in service provision in the Public Institution for Social Security.

\section{Significance of the Research}

The importance of the study comes from the need to identify human competencies and their impact on institutional excellence, and this study derives its importance through its useful contributions, both theoretical and practical.

\section{Research Hypotheses}

The importance of the study comes from the need to identify human competencies and their impact on institutional excellence, and this study derives its importance through its useful contributions, both theoretical and practical:

HO.1: There is no statistically significant effect at a significant level ( $\alpha \leq 0.05)$ of human competencies with their dimensions (efficiency, knowledge, good behavior, skills) on institutional excellence in its dimensions (leadership excellence, service excellence) in the Social Security Corporation

H01. 1: There is no statistically significant effect at the level $(\alpha \leq 0.05)$ of human competencies with its dimensions (efficiency, knowledge, good behavior, skills) on leadership excellence in the public institution for social security.

H01.2 There is no statistically significant effect at the level $(\alpha \leq 0.05)$ of human competencies 
with its dimensions (efficiency, knowledge, good behavior, skills) on leadership excellence in the public institution for social security.

\section{Research Model}

Figure No. (1) shows the relationship between the study variables, and to achieve the purpose of the study and know the impact of the independent variables (human

competencies) on the dependent variable (institutional excellence), and based on several references, a model was designed below for the study:

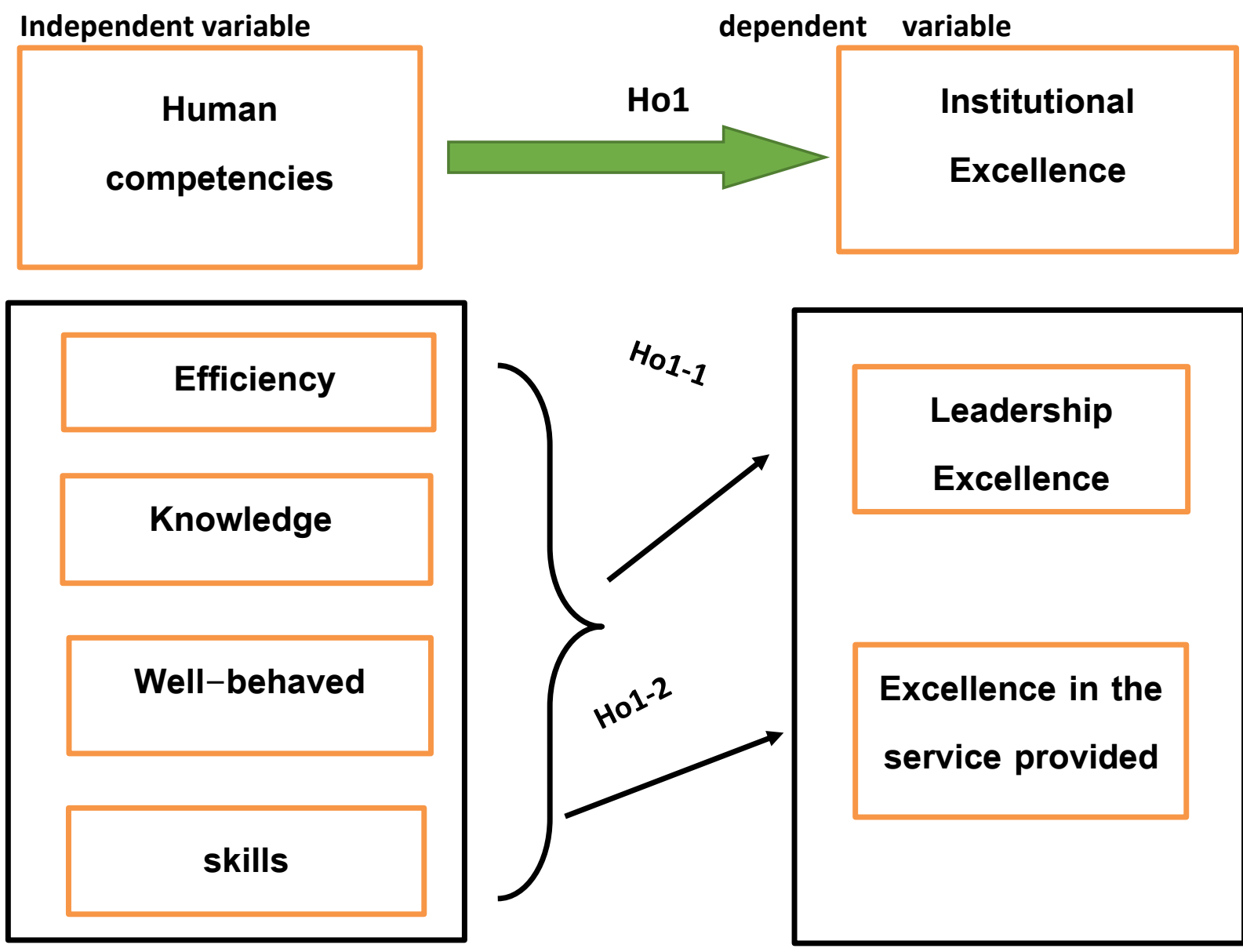

1-7. Figure 1: Study model: The model was prepared by the researchers based on the sources in Table (1).

Table (1) References to the search form

\begin{tabular}{|l|l|}
\hline $\begin{array}{l}\text { Sources } \\
\text { (Ahmed, 2014), (Madani, 2015), (Nihal, 2015), } \\
\text { (Manal, 2016) }\end{array}$ & $\begin{array}{l}\text { Human competencies, Its dimensions } \\
\text { (competence, knowledge, good behavior, skills) }\end{array}$ \\
\hline $\begin{array}{l}\text { (Tawfiq, 2019), (Asila and Aisha, 2016) (Fathiya, } \\
\text { 2014), (Al-Azzawi, 2010). }\end{array}$ & $\begin{array}{l}\text { Institutional Excellence, Its dimensions } \\
\text { (leadership excellence, service excellence) }\end{array}$ \\
\end{tabular}

Theoretical framework of the study and related previous studies) Conceptual and Operational Definitions (2-1. 
Human competencies: making good use of resources. The administration has the responsibility to use the human, financial and material elements in the best use, i.e. efficiently. The efficiency also refers to the individual's ability to apply his learning in a proper manner characterized by accuracy and mastery, taking into account the human dimension in dealing with others (Adwan, 2011).

It is also known as an intellectual style and a management philosophy that depends on how to achieve the desired results in order to reach the satisfaction of all the needs of the parties, whether workers in the organization, customers or society as a whole within the framework of knowledge, human capital, creativity and the ability for continuous performance (Najwa, 2020).

It is known (procedurally) that human competencies are one of the basic components and the important and basic element for the success of the institution, as the presence of human resources with high efficiency and responsibility enables it to carry out the workload and achieve the goals of the organization and use its available material potential with the highest efficiency. social security.

Efficiency: The ability to carry out a set of specific tasks, which is measurable and observable in the activity and, more broadly, is the willingness to recruit and put resources (Al-Qaouri, 2012).

It is defined procedurally: it is the extent of investment and optimal use of the available resources (financial, human, material) in the institution and working to achieve the set goals at the lowest costs during operations. And its impact will be measured through the paragraphs of the questionnaire in the General Organization for Social Security.

Knowledge: It relates to a set of organized, assimilated and integrated information in a frame of reference that allows the institution to direct its activities and work in special circumstances, and it can be mobilized in order to provide different interpretations, partial and even contradictory. pre-existing in order to develop not only the content of the activity but also the structure and method of obtaining it (Harington, 2008).

It is defined procedurally: it is awareness, awareness, understanding the facts, the employee's acquisition of experiences and skills through experience, benefiting from others and selfdevelopment. Its impact will be measured through the questionnaire items in the Social Security Corporation.

Good behavior: the individual's ability to carry out tasks and exercise his competencies successfully, as it is linked to the identity and will of the individual and motivates him to perform his tasks as best, he can (Pinar \& Girard, 2008).

It is procedurally defined as the individual's ability to carry out all the tasks that are entrusted to the employee, as their impact will be measured through the questionnaire items in the Social Security Institution.

Skills: The ability to implement and work tangibly according to a predetermined process and goals, and this makes the skill more implicit and technical and difficult to transfer (Abdul Mohsen, 2013).

Procedurally defined: as the ability to carry out tasks and duties within the objectives previously set by the organization. Its impact will be measured through the questionnaire items in the Social Security Corporation.

Institutional Excellence: A state of administrative creativity and organizational excellence to achieve extraordinarily high levels of performance and implementation of production, marketing, financial and other processes in the organization, resulting in results and 
achievements that surpass those achieved by competitors, and are satisfied by customers and all stakeholders in the organization (Adwan, 2011).

It is also defined as every action or activity of each person that enhances and strengthens achievement within the organization and includes many work forces that make up the structure of the organization (Najwa, 2020). Excellence is a holistic and comprehensive concept that does not accept division in the sense that it is not possible to imagine an organization distinct in a particular field while its performance collapses in the rest of the fields. Excellence and the other is that all the actions and decisions issued by the administration and the systems and activities it adopts are distinguished, and the two dimensions are complementary and considered two sides of the same coin and one cannot be achieved without the other (Madani, 2015).

It is defined procedurally: the organization's pursuit of prior opportunities by strategic planning and the constant quest to develop and sustain the provision of new value to customers and to the owners of the institution by anticipating their needs and meeting them and doing everything in its power to maintain positive competitive performance that achieves institutional excellence. One of the most important foundations on which institutional excellence is based is the presence of a distinguished leadership that always strives for creativity, innovation, development, continuous improvement and strategic planning, whose main objective is to anticipate the future needs of workers, the owners of the institution and the community, and to take into account the balance in meeting these needs and interests. Achieving this by activating the modern practices of human competencies to provide this resource. And its impact will be measured through the paragraphs of the questionnaire in the General Organization for Social Security.

Leadership Excellence: The ability to motivate individuals to be willing and voluntarily committed to achieving or exceeding organizational goals (Hassan, 2009).

It is defined procedurally: as the ability to direct and employ individuals to carry out their tasks in the required manner, and to follow up on the work of employees. And its impact will be measured through the paragraphs of the questionnaire in the General Organization for Social Security.

Excellence in Service Delivery: All vital internal activities and events that distinguish the institution from other institutions through which the needs, expectations and aspirations of customers are met (Al-Qaouri, 2012).

It is defined procedurally: as what distinguishes the services provided by one organization over the services provided by another organization. Its impact will be measured through the paragraphs of the questionnaire in the General Organization for Social Security

\section{Human Competencies}

Competencies are considered the foundation of the institution because they are of a cumulative nature on the one hand, and are difficult to imitate by competitors on the other hand, as this concept has received a large share of the attention of those looking for excellence and success, even if their views differ, they share several basic points and we will try to clarify them in this area through Addressing the concept of competencies, their characteristics and importance, the dimensions of competencies as well as their types and requirements

The Concept of Human Competencies

The concept of competencies in general is considered one of the problems related to the 
management of human resources, as the capabilities and competencies enjoyed by employees must be identified and compared with the necessary competencies that achieve the goals of the institution. Therefore, businessmen must differentiate between the two terms (Ahmed, 2014), given the multiplicity of opinions and their sometimes-different definitions, especially when discussing the effectiveness of management. This is reflected in the following:

\section{Efficiency}

The first definition: Effectiveness is defined as the extent to which the organization achieves its goals. If the administration achieves its goals, it is described as effective and less effective if it does not achieve its goals as required (Omar, 2015).

The second definition: It is also known as making the workforce successfully accomplish what is required of them, and it is said that the successful manager is the effective manager, and the term "effectiveness" refers to the need to complete the right work in the right manner at the right time (Madani, 2015).

Efficiency:

The first definition: It is the sum of three types of knowledge: theoretical knowledge, scientific knowledge (experience) and a behavioral dimension, i.e., being (packed or mobilable, used by the individual to accomplish his tasks in a better way) (Galeh, 2015).

The second definition: Competence is that immediate and short practical skill (Saleem, 2020). 2-Dimensions of competencies: The dimensions of human competencies are divided into the following:

First: knowledge

It relates to a set of organized, assimilated and consolidated information in a frame of reference that allows the organization to direct its activities and work in special circumstances, and it can be mobilized to provide different interpretations, partial and even contradictory. In order to develop not only the content of the activity but also the structure and method of obtaining it (Saleem, 2020).

Second: skill

It is the ability to implement and work tangibly according to a predetermined process and goals, and this is what makes the skill more implicit and technical and difficult to transfer (Ahmed, 2014).

Third: good behavior

The individual's ability to carry out tasks and practice his competencies successfully, as it is linked to the identity and will of the individual and motivates him to perform his tasks as well as he can (Allah, 2017)

\section{Institutional Excellence}

Institutions achieve the highest possible level of quality, mastery, and excellence; It is a matter and a very urgent and necessary requirement, and it cannot be ignored or neglected, especially since we are living in an era of rapid development and change, the era of the tremendous knowledge revolution and the terrible technological and technical progress, an era that only recognizes the distinguished and competent, whether they are individuals or institutions, especially in light of International competitiveness in achieving leadership and leadership in excellence and quality in the various fields of life and work, especially as the requirements of the labor market have changed dramatically, as the labor market has become accepted only by the distinguished and qualified graduate who possesses a lot of capabilities, 
knowledge and experiences (Taresh, 2015).

All of this requires us all to find ways to adapt and keep pace with the changes and requirements of this era and to deal with them in a sustainable manner, on top of which is achieving excellence and quality in performance, whether at the level of individuals or institutions; The global field of work, which is no longer separated by the boundaries of place or others, has become accepts only distinguished, competent and qualified people who possess many specialized and qualitative skills in many fields. Therefore, it has become a duty and necessary for various institutions to move strongly towards the industry of excellence and to direct and harness all their capabilities. Human and material resources in order to achieve total quality in institutional performance (Aya and Kamal, 2018).

Dimensions of institutional excellence: The dimensions of institutional excellence are as follows:

Leadership Excellence2.5.3.1

It is a distinguished leadership style, and a management philosophy that stems from the necessity of the leaders' interest in any organization with all its employees. This attention focuses on the type of leadership style, and its interest in dealing with employees according to authentic values and principles, treating them with appreciation, respect, justice, equality, transparency and credibility; Which contributes to the positive impact of their performance and raises their loyalty and love for their organization, as they consider themselves partners in it, and in a way that achieves a competitive advantage for the organization and compared with other organizations as values are the guide and motivator for the behavior of individuals. It is the process of persuasion or setting an example that an individual or a leadership team uses to serve a group of individuals in pursuit of goals the leader wants, or to achieve common goals between the leader and his followers (Taie, 2015).

\section{Excellence in the service provided}

This standard examines the procedures for developing and implementing the processes that the institution uses to provide basic products and services by measuring the effectiveness of the procedures followed by the institution in many areas, including: determining the requirements of the beneficiaries or recipients of the service, managing the production or service processes within the institution to be able to achieve its objectives, and gaining satisfaction Beneficiaries and taking their opinions or observations (feedback), and managing relationships with suppliers and service providers to ensure that products or services needed by the organization are provided in an efficient manner, and the ability for continuous improvement (Auranzeb \& Bhutto, 2015).

All categories of dealers are considered consumers of goods and services, and when a commodity is obtained that meets the needs of the categories of dealers or increases their expectations, these dealers resort to competitors to deal with them, and under the management of excellence, resorting to these results is an indication that something has happened An error or error is made in the processes that led to the production of these products or services, and these symptoms lead to an action plan, to correct these errors or deficiencies (Vrchota, et. al, 2020).

\section{Related Previous Studies}

Najwa Study (2020):

This study aimed to demonstrate the impact of human resource management practices on 
achieving institutional excellence, as it was a field study for 6 October University, Giza Governorate. The study relied on the analytical survey method, and a questionnaire was designed and distributed to the study sample consisting of (100) employees in the human resources department, their managers, directors of various departments, institution leaders, managers and their representatives at October 6 University, Giza Governorate - Egypt. The results of the study showed that there is a positive relationship between human resource management consulting practices and institutional excellence, and this relationship is statistically significant, which means that there is a statistically significant relationship between human resource management consulting practices and institutional excellence. The results of the study also indicated that there is a statistically significant relationship between the specialized practices of human resource management and institutional excellence. As well as the existence of a statistically significant relationship between the administrative practices of human resource management and institutional

Excellence.

Tawfiq's study (2019):

The study showed that in light of the intensity of competition and the emergence of the knowledge economy, competencies are considered the renewable reservoir of creative capabilities and the decisive factor in the distinction of contemporary organizations, and their role goes beyond being a production element to the controller and regulator of other production elements without performance. The latter is determined by the interaction of two main factors; The first is the ability that competencies possess exclusively or have the ability to mobilize, while the second is represented in the desire that the stimulus process allows to provoke by directing human behavior towards the desired behavior. Motivation in general and material motivation in particular comes as a response mechanism to the last challenge on the one hand and as a solid base for establishing moral motivation on the other hand, and therefore the forms raised in this regard revolve around the extent of the impact of this type of motivation (material stimulation) on the performance of that distinctive type of human resources (competencies).

In order to identify the reality of the companies from this angle, a field study was conducted at Ain Al-Tuta Cement Company - Batna - by directing a questionnaire to its tires and treating it through a set of statistical tools and using the SPSS statistical program. The results were as follows:

There is an acceptable level of material motivation in the company from the point of view of its employees.

There is a high level of performance in the company from the point of view of its employees. There is an inverse relationship with a weak effect between wages and performance due to the negative impact of wages on self-motivation.

\section{(2016) Asilah and Aisha Study}

The study showed that the rapid dynamic changes that the world knows had had a significant impact on the institutions that became active. In one word, the system opened today, and thus these institutions guarantee their continuity in an atmosphere of competition, which are competencies, and mainly the passage in the knowledge economy based on resources that have a non-nature concrete.

The study also showed that the competitive advantage is linked to the location in front of the external environmental conditions, but the capabilities of institutions to exploit their internal resources, whose competencies are one of their basic elements. On the changes that take 
place at the level of its environment, a factor that perceives privacy.

Fethiye Study (2014):

The study showed that by addressing the most important aspects of the subject, both theoretical and practical, it reached an answer to the questions raised, as the recorded results can be highlighted as follows:

- The institution can be seen as a portfolio of resources and competencies controlled by the institution in a way that it can rely on in the preparation and implementation of its strategies, thus enhancing its efficiency and effectiveness.

- Competencies have no meaning if they are not characterized by the flexibility that allows them to respond to the various changes that occur at the ocean level, especially in light of the rapid changes that the world is witnessing and the degree of its complexity and instability.

- The competitive advantage does not lie in the institution's resources, but in the way of merging these resources, and the resulting tangible differences in how they penetrate the markets and their location, which is provided by human competencies, which made them appear as a focal point.

\section{Al_Aina \& Atan (2020) The Impact of Implementing Talent Management Practices on Sustainable Organizational Performance}

This study aimed to investigate the impact of competency management practices on sustainable organizational excellence in real estate companies located in the United Arab Emirates. This study seeks to make contributions through an empirical evaluation of competency management in the United Arab Emirates. A structured questionnaire was distributed to collect data from a study sample of 306 managers working in real estate companies. The proposed hypotheses were verified by SEM structural equation modeling. The results of this study show that talent attraction and talent retention had no effect on sustainable organizational excellence, while learning, development and career management were found to have significant positive effects. The study suggests that learning and development, and professional management of employees, should be enhanced by management by focusing on training, training and job rotation programs so that the company can achieve sustainable organizational performance.

\section{Olwan et, all. (2019) Strategic Leadership Competencies and its Impact on Achieving Organizational Excellence via the Mediating Role of Organizational Commitment: A Case Study in National Center for Security and Crisis Management (NCSCM)}

This study aimed to reveal the reality of implementing strategic leadership, in addition to testing the cause-and-effect relationship between strategic leadership and organizational excellence through the mediating role of organizational commitment. The National Center for Security and Crisis Management was selected as a target group for the current study; As an organization it has a great responsibility to exercise strategic leadership which is closely linked to the staff of the center. The study followed the descriptive analytical approach by reviewing the theoretical literature and previous studies related to the study variables. The questionnaire was used as a tool to collect data from the members of the study community in the center, which consisted of 160 members. Arithmetic means, standard deviations, simple regression coefficients and multiple regression coefficients were used to test the study's hypotheses and answer its questions. The results of the study showed a high level of strategic leadership in addition to organizational excellence and organizational commitment. There was a significant effect of strategic leadership and organizational commitment on 
organizational excellence at the level of significance $(\alpha \leq 0.05)$, and a significant effect of the mediating factor at the level of significance $(\alpha \leq 0.05)$. One of the study's main recommendations for the National Center for Security and Crisis Management was to "identify future opportunities based on information from various sources."

\section{Jabbouri \& Zahari (2014) The Impact of Human Competencies on Job Excellence}

This study discusses the impact of core competencies on organizational excellence as a critical issue in the Iraqi private banking sector. A questionnaire was developed and submitted to 10 private banks, and the study sample included 200 managers in these banks. The hypothesis of testing the study variables was accommodated in a questionnaire with Cronbach's alpha coefficient of $75 \%$ and was prepared based on a number of measures related to the subject of the study. A set of methods were used to analyze the statistical data, and the results were extracted using the SPSS program. The result shows that there is a significant relationship between core competencies and organizational excellence. Accordingly, the study recommended that the bank's management develop the core competencies of human resources as a strategic tool to enhance organizational excellence and expand their empirical knowledge in the context of private banks in Iraq.

\section{Procedures and Methodology}

First: Study Methodology

The study relies on the descriptive analytical approach to test the impact of human competencies practices with their dimensions (efficiency, knowledge, good behavior, skills) on institutional excellence in its dimensions (leadership excellence, service excellence) by reviewing relevant previous studies, and using the questionnaire as a tool for data collection that will cover the results Analyzed the practical side of the study.

\section{3-1. Study population and sample}

The study population consists of all employees in the Jordanian Social Security Corporation, whose number is (475) employees, according to the data published by the Social Security Corporation. As for the study sample, it is a random sample, selected from working employees from the upper and middle administrative levels in the Social Security Corporation from During the electronic distribution of the questionnaire (the study tool) by placing it on the institution's website, where the percentage of representation of the study sample consisted of (141) male and female employees, and this percentage is acceptable according to Uma Sekaran (2013).

\section{Fourth: The Study Tool}

The previous studies were relied on to develop the study tool represented in collecting primary data. The questionnaire will consist of three parts, the first part of which will relate to the demographic and functional data of the members of the sampling unit, and the second part of which will consist of a set of paragraphs to measure the dimensions of the independent variable (human competencies), The third part will consist of a set of paragraphs to measure the dimensions of the dependent variable (institutional excellence). This is according to the five-point Likert scale, as follows: (strongly agree, agree, neutral, disagree, strongly disagree).

Fifth: The validity and reliability of the tool:

Validity of the Study Tool 
The validity of the study tool was verified and presented to a group of specialized and experienced arbitrators from faculty members in the departments of management colleges in different Jordanian universities.

Stability of the study instrument:

To verify the stability of the study tool, the stability coefficients were calculated by Cronbach's alpha method, to identify the internal consistency of the paragraphs

Statistical methods used

To answer the study questions and test the hypotheses, the data will be processed using the Statistical Package for the Social Sciences: SPSS, where the following statistical analyzes were used:

1-Frequencies and percentages to describe the demographic and functional characteristics of the study sample members.

2-Arithmetic averages and standard deviations of the study tool items and areas

3-Cronbach Alpha internal consistency coefficient to verify the stability of the study tool

4-Multiple regression analysis in order to measure the effect of the dimensions of the independent variables on one dependent variable.

Statistical methods used

To answer the study questions and test the hypotheses, the data will be processed using the Statistical Package for the Social Sciences: SPSS, where the following statistical analyzes were used:

1-Frequencies and percentages to describe the demographic and functional characteristics of the study sample members.

2-Arithmetic averages and standard deviations of the study tool items and areas

3-Cronbach Alpha internal consistency coefficient to verify the stability of the study tool

4-Multiple regression analysis in order to measure the effect of the dimensions of the independent variables on one dependent variable.

Table(2) Cronbach's internal consistency coefficient alpha

\begin{tabular}{|l|l|l|}
\hline $\begin{array}{l}\text { number of } \\
\text { paragraphs }\end{array}$ & $\begin{array}{l}\text { Cronbach's alpha } \\
\text { coefficient }\end{array}$ & The field \\
\hline \multicolumn{2}{|l|}{ The independent variable: human competencies } \\
\hline 5 & .814 & Efficiency \\
\hline 5 & .874 & Knowledge \\
\hline 5 & .911 & Behaving in a good manner \\
\hline 5 & .917 & Skills \\
\hline 20 & .954 & The independent variable as a whole \\
\hline Dependent variable: organizational excellence \\
\hline 5 & .871 & Leadership Excellence \\
\hline 5 & .885 & Excellence in the service provided \\
\hline 10 & .935 & The dependent variable as a whole \\
\hline 30 & .967 & The tool as a whole \\
\hline
\end{tabular}

It is clear from the above table that all fields of resolution have a high and medium stability, and all alpha values are higher than (0.70), which is an indication of high stability of the fields, and it is an acceptable percentage for conducting the study, as Cronbach's alpha coefficient is between (1) and (0), In general, if the alpha is less than (0.4), the stability has a low value, and the paragraphs are considered to have medium stability, as their value is between (0.4-0.7), while the stability is considered high if its value is higher than 
(0.7).

\section{The Characteristics of the Study Sample}

A set of demographic and personal characteristics of the study sample members were relied on (gender, age, educational qualification, years of experience).

.The results of the descriptive statistical analysis of the study variables

The Independent Variable: Human Competency Practices

The researchers dealt with four dimensions of the independent variable (human competency practices) and the arithmetic means and standard deviations were extracted according to the table below.

The arithmetic averages and standard deviations of the independent variable were extracted from the human competency practices with its dimensions, and the table below illustrates this:

\section{Table(3)}

Arithmetic averages and standard deviations of human competency practices with their dimensions, arranged in descending order according to their arithmetic mean

\begin{tabular}{|l|l|l|l|l|l|}
\hline level & $\begin{array}{l}\text { Standard } \\
\text { deviation }\end{array}$ & SMA & The field & $\begin{array}{l}\text { Num } \\
\text { ber }\end{array}$ & Rank \\
\hline high & .729 & 3.80 & Knowledge & 2 & 1 \\
\hline middle & .775 & 3.66 & Behaving in a good manner & 3 & 2 \\
\hline middle & .741 & 3.61 & Efficiency & 1 & 3 \\
\hline middle & .912 & 3.16 & skills & 4 & 4 \\
\hline middle & & $\mathbf{3 . 5 5}$ & $\begin{array}{l}\text { Arithmetic mean in human } \\
\text { competency practices as a whole }\end{array}$ & & \\
\hline
\end{tabular}

Dependent variable: organizational excellence

The arithmetic means and standard deviations of the dependent variable institutional excellence with its dimensions were extracted, and the table below illustrates this.

Table) 4( Arithmetic averages and standard deviations of institutional excellence in its dimensions arranged in descending order according to their arithmetic means

\begin{tabular}{|l|l|l|l|l|l|}
\hline level & $\begin{array}{l}\text { Standard } \\
\text { deviation }\end{array}$ & SMA & Dimensions used & $\begin{array}{l}\text { Num } \\
\text { ber }\end{array}$ & Rank \\
\hline middle & .722 & 3.57 & Excellence in the service provided & 2 & 1 \\
\hline middle & .821 & 3.44 & Leadership Excellence & 1 & 2 \\
\hline middle & & 3.50 & Institutional Excellence & & \\
\hline
\end{tabular}

The results of testing the hypotheses of the study:

Before starting to test the hypotheses, a number of tests were used to verify the appropriateness of the data, which are:

Normal distribution test

The normal distribution of the dependent variable, which is institutional excellence with its dimensions (leadership excellence, service excellence), was tested by testing the Kolmogroov-Smirnov $Z$ values as shown in the following table (5): 
Table (5) Normal distribution of the data

\begin{tabular}{|l|l|l|l|}
\hline $\begin{array}{l}\text { Organizational } \\
\text { excellence as a } \\
\text { whole }\end{array}$ & $\begin{array}{l}\text { Excellence } \\
\text { in the } \\
\text { service } \\
\text { provided }\end{array}$ & $\begin{array}{l}\text { Leadership } \\
\text { Excellence }\end{array}$ & \\
\hline 141 & 141 & 141 & Sample volume \\
\hline 3.50 & 3.57 & 3.44 & SMA \\
\hline .771 & .722 & .821 & standard deviation \\
\hline .042 & .093 & .060 & Absolute \\
\hline .036 & .073 & .060 & Positive \\
\hline$-.042-$ & $-.093-$ & $-.056-$ & Negative \\
\hline .653 & 1.447 & .925 & Kolmogorov-Smirnov Z \\
\hline .788 & .130 & .360 & Indication level -Sig \\
\hline
\end{tabular}

Table (05) shows that the dependent variable as well as all its dimensions follow a normal distribution because the Kolmogroov-Smirnov $Z$ values $(.925,1.447,1.472$, .653 ) are less than 1.96, and the Sig level for each is greater than 0.05 .

\section{Multi-collinearity}

Using the linear correlation test in order to ensure that there is no high correlation between the independent variables, by relying on the Variance Inflation Factor VIF test, and the Tolerance test for each of the independent variables, where the independent variables of the model must be independent Among them, and to ensure that purpose, we use this test, which is considered one of the ways to get rid of the problem of multilinearity, knowing that the coefficient of variation inflation must not exceed the value (10), and the value of the permissible variance test must be greater than (0.05), and by calculating the coefficients Previous for all independent variables, the obtained results were listed in Table (6) as follows:

Table (6) Variance inflation coefficient and permissible variance test for the study variables

\begin{tabular}{|l|l|l|}
\hline VIF & Tolerance & independent variables \\
\hline 2.355 & .425 & Efficiency \\
\hline 1.990 & .503 & Knowledge \\
\hline 2.617 & .382 & $\begin{array}{l}\text { Behaving in a good } \\
\text { manner }\end{array}$ \\
\hline 2.872 & .348 & skills \\
\hline
\end{tabular}

Table (6) shows that the test values of variance inflation for all variables are less than (10), while the value of the test of permissible variance for all variables is greater than (0.05), and therefore it can be said that there is no problem of high correlation between the variables, and this indicates that there is no There is a statistically significant correlation between the independent variables mentioned in the (correlation) table, and this enhances the possibility of their use.

To answer the first main question, which is, is there an impact of the practices of human competencies with their dimensions (competence, knowledge, good behavior, skills) on institutional excellence in its dimensions (leadership excellence, service excellence) in the Social Security Corporation The following hypotheses were tested.: 
First hypothesis H01: There is no statistically significant effect at the level of significance ( $\alpha \leq 0.05$ ) for human competencies with their dimensions (efficiency, knowledge, good behavior, skills) in institutional excellence in its dimensions (leadership excellence, service excellence) in the Social Security Corporation.

To verify the validity of this hypothesis, a multiple regression analysis of the impact of human competency practices with its dimensions (efficiency, knowledge, good behavior, skills) on institutional excellence was used in its dimensions (leadership excellence, service excellence) in the Social Security Corporation, as shown in the following tables.

Table (7) Summary of the model for the impact of human competency practices on institutional excellence

\begin{tabular}{|l|l|l|l|l|}
\hline Standard error & $\begin{array}{l}\text { Modified } \\
\text { parameter) R }\left(\begin{array}{l}\text { Coefficient of } \\
\text { determination } \\
\left(\mathbf{R}^{2}\right)\end{array}\right.\end{array}$ & $\begin{array}{l}\text { correlation } \\
\text { coefficient (R) }\end{array}$ & model \\
\hline .465 & .554 & .561 & .749 & 1 \\
\hline
\end{tabular}

The table shows the results of the summary of the model to test the main hypothesis, as it appears that the value of the correlation coefficient between the independent variable (the practices of human competencies) and the dependent variable (institutional excellence) together amounted to (.749), which indicates the existence of a medium positive correlation between the variables, and the table shows Also, the value of the coefficient of determination (R2) is (.561), meaning that the model explained the proportion of (56.1\%) of the total variance of the dependent variable (institutional excellence), while the rest is explained by other factors.

Table (8) Results of multiple regression analysis of the impact of human competency practices on organizational excellence ANOVA

\begin{tabular}{|l|l|l|l|l|l|l|}
\hline $\begin{array}{l}\text { Indication } \\
\text { level } \\
\text { moral for } \\
\text { F sig }\end{array}$ & $\begin{array}{l}\text { The } \\
\text { calculated(F) } \\
\text { value }\end{array}$ & $\begin{array}{l}\text { mean } \\
\text { squares }\end{array}$ & $\begin{array}{l}\text { degrees } \\
\text { of } \\
\text { freedom }\end{array}$ & $\begin{array}{l}\text { sum of } \\
\text { squares }\end{array}$ & data source & model \\
\hline .000 & 75.504 & 16.307 & 4 & 65.229 & Regression & \\
\hline & & .216 & 236 & 50.971 & $\begin{array}{l}\text { Residual } \\
\text { (error) }\end{array}$ & 1 \\
\hline & & & 240 & 116.201 & Total & \\
\hline
\end{tabular}

The table shows the results of the analysis of regression variance practices of human competencies on institutional excellence, where the table shows the calculated $F$ value, which indicates the suitability of the model to the regression test, and that the relationship between the independent and dependent variables follows the linear model, reaching (75.504) at the level of significance (). 000) The decision rule states that the model is considered appropriate if the value of the level of significance for (sig) is less than (0.05), and depending on the results obtained, the null hypothesis is rejected and the alternative hypothesis is accepted, which states (there is a statistically significant effect at the level of significance ( $\alpha \leq 0.05)$ for human competencies with its dimensions (efficiency, knowledge, good behavior, skills) in 
institutional excellence with its dimensions (leadership excellence, service excellence) in the social security institution.

Table (8) Transaction results for the impact of human competency practices on institutional excellence

\begin{tabular}{|l|l|l|l|l|l|}
\hline \multirow{2}{*}{$\begin{array}{l}\text { Indication } \\
\text { level- sig }\end{array}$} & \multirow{2}{*}{ Values t } & $\begin{array}{l}\text { Standard } \\
\text { coefficients }\end{array}$ & \multicolumn{2}{|l|}{$\begin{array}{l}\text { non-standard } \\
\text { transactions }\end{array}$} & \multirow{2}{*}{$\begin{array}{l}\text { independent } \\
\text { variables }\end{array}$} \\
\cline { 3 - 6 } & Values Beta & $\begin{array}{l}\text { standard } \\
\text { error }\end{array}$ & $\begin{array}{l}\text { Values } \\
\text { B }\end{array}$ & \\
\hline .000 & 4.066 & & .181 & .736 & Constant \\
\hline .107 & 1.619 & .107 & .062 & .101 & Efficiency \\
\hline $.036^{*}$ & 2.106 & .128 & .058 & .122 & Knowledge \\
\hline $.000^{*}$ & 6.610 & .461 & .063 & .414 & $\begin{array}{l}\text { Behaving in a good } \\
\text { manner }\end{array}$ \\
\hline .054 & 1.938 & .142 & .056 & .108 & skills \\
\hline
\end{tabular}

The table shows the results of the coefficients for the impact of the impact of human competency practices with their dimensions (efficiency, knowledge, good behavior, skills) on institutional excellence with its combined dimensions. Significant significance sig $(.036, .000)$ and based on the decision rule related to $t$, which states that the null hypothesis is rejected if the significant value of $t$ is less than (0.05). This result shows that there is a problem in the competence and skills of employees in the Social Security Institution.

The null hypothesis will be rejected for the two dimensions (efficiency and skills) in the sense that there is a statistically significant effect of them on institutional excellence, while the two dimensions (knowledge, good behavior) have no significant effect on institutional excellence, meaning that their effect is apparent and not significant, where the value of $t$ was (1.619, $1.938)$ and the significance value $(.107, .054)$ is greater than.(0.05)

The table also shows the values of the standard Beta coefficients, as it is clear that the highest dimensions affecting institutional excellence were good behavior, as the value for Beta. (461.) was

\section{Sub-hypothesis Test Results}

The first sub-question: Is there an impact of the practices of human competencies in their dimensions (competence, knowledge, good behavior, skills) on leadership excellence in the Social Security Institution?.

H01.1: There is no statistically significant effect at the level ( $\alpha \leq 0.05$ ) of human competencies with its dimensions (competence, knowledge, good behavior, skills) on leadership excellence in the Social Security Institution.

To answer this question and verify the validity of this hypothesis, a multiple regression analysis of human competencies practices with its dimensions (competence, knowledge, good behavior, skills) was used in leadership excellence in the Social Security Institution, as shown in the following tables. 
Table (9) Summary of the model for the impact of human competency practices on leadership excellence

\begin{tabular}{|l|l|l|l|l|}
\hline standard error & $\begin{array}{l}\text { Modified } \\
\text { coefficient }(\mathbf{R})\end{array}$ & $\left.\mathbf{( R}^{2}\right)$ & $\mathbf{( R )}$ & model \\
\hline .531 & .553 & .560 & .748 & 1 \\
\hline
\end{tabular}

The table shows the results of the summary of the model to test the first sub-hypothesis, as it is seen that the value of the correlation coefficient between the independent variable (practices of human competencies), and after the dependent variable (leadership excellence) amounted to (.748), which indicates the existence of a medium positive correlation between the variables. The table also shows that the value of the coefficient of determination (R2) (.560), that is, the model explained (56\%) of the total variance of the variable (leadership excellence), while the rest is explained by other factors.

Table (10) Results of multiple regression analysis of the impact of human competency practices on leadership excellence ANOVA

\begin{tabular}{|l|l|l|l|l|l|l|}
\hline $\begin{array}{l}\text { Indication level } \\
\text { Significance for } \\
\text { F- sig }\end{array}$ & $\begin{array}{l}\text { The } \\
\text { calculated } \\
\text { F value }\end{array}$ & $\begin{array}{l}\text { mean } \\
\text { squares }\end{array}$ & $\begin{array}{l}\text { degrees } \\
\text { of } \\
\text { freedom }\end{array}$ & $\begin{array}{l}\text { sum of } \\
\text { squares }\end{array}$ & data source & model \\
\hline .000 & 75.142 & 21.162 & 4 & 84.649 & Regression & \\
\hline & & .282 & 236 & 66.464 & Residual & \multirow{2}{*}{1} \\
\hline & & & 240 & 151.114 & Total & \\
\hline
\end{tabular}

The table shows the results of regression variance analysis of the impact of human competency practices on leadership excellence, where the table shows the calculated $F$ value, which indicates the suitability of the model to the regression test, and that the relationship between the independent and dependent variables follows the linear model, reaching (75.142) at the level of significance ( .000) The decision rule states that the model is considered appropriate if the value of the significance level of (sig) is less than (0.05), and depending on the results obtained, the null hypothesis is rejected and the alternative hypothesis is accepted, which states (a statistically significant effect at the level of (.000). ( $\alpha$ $\leq 0.05$ ) for human competencies with their dimensions (efficiency, knowledge, good behavior, skills) in leadership excellence in the Social Security Institution).

The second sub-question: Is there an impact of the practices of human competencies in their dimensions (competence, knowledge, good behavior, skills) on excellence in service provision in the social security institution?

H01.2: There is no statistically significant effect at the level $(\alpha \leq 0.05)$ of human competencies with its dimensions (efficiency, knowledge, good behavior, skills) in the service excellence provided in the Social Security Institution.

To answer this question and verify the validity of this hypothesis, a multiple regression analysis of human competency practices with its dimensions (efficiency, knowledge, good behavior, skills) was used in service excellence in the social security institution, as shown in the following tables. 
Table (11)

Summary of the model for the impact of human competency practices in service excellence

\begin{tabular}{|l|l|l|l|l|}
\hline standard error & $\begin{array}{l}\text { Modified } \\
\text { coefficient (R) }\end{array}$ & $\begin{array}{l}\text { coefficient of } \\
\text { determination } \\
\text { (R2) }\end{array}$ & $\begin{array}{l}\text { correlation } \\
\text { coefficient (R) }\end{array}$ & model \\
\hline .567 & .524 & .532 & .729 & 1 \\
\hline
\end{tabular}

The table shows the results of the summary of the model to test the first subhypothesis, as it is seen that the value of the correlation coefficient between the independent variable (the practices of human competencies) and the dimension of the dependent variable (excellence in service provision) reached (.729), which indicates the existence of a medium positive correlation between The table also shows that the value of the coefficient of determination (R2) (.532), that is, the model explained the percentage (53.2\%) of the total variance of the variable (excellence in service provision), while the rest is explained by other factors.

Table (12)

Results of multiple regression analysis of the impact of human competency practices on excellence in service delivery ANOVA

\begin{tabular}{|l|l|l|l|l|l|l|}
\hline $\begin{array}{l}\text { Indication level } \\
\text { Significance for } \\
\text { F- sig }\end{array}$ & $\begin{array}{l}\text { The } \\
\text { calculated } \\
\text { F value }\end{array}$ & $\begin{array}{l}\text { mean } \\
\text { squares }\end{array}$ & $\begin{array}{l}\text { degrees } \\
\text { of } \\
\text { freedom }\end{array}$ & $\begin{array}{l}\text { sum of } \\
\text { squares }\end{array}$ & data source & model \\
\hline .000 & 66.972 & 21.506 & 4 & 86.023 & Regression & \multirow{2}{*}{1} \\
\hline & .321 & 236 & 75.783 & Residual & \\
\hline
\end{tabular}

The table shows the results of regression variance analysis of the impact of human competency practices on excellence in service provision, where the table shows the calculated $\mathrm{F}$ value, which indicates the suitability of the model to the regression test, and that the relationship between the independent and dependent variables follows the linear model, reaching (66.972) at the level of Significance (.000) and the decision rule states that the model is considered appropriate if the value of the level of significance for (sig) is less than (0.05), and depending on the results obtained, the null hypothesis is rejected and the alternative hypothesis is accepted, which states (there is a statistically significant effect At the level ( $\alpha \leq$ 0.05 ) of human competencies with their dimensions (efficiency, knowledge, good behavior, skills) in the service excellence provided in the social security institution.

\section{Discuss the Study Results, Recommendations, and Conclusion \\ Discussing the Results of the Study}

The results of the first main question, "Is there an impact of human competency practices with their dimensions (efficiency, knowledge, good behavior, skills) on institutional excellence in its dimensions (leadership excellence, service excellence) in the social security 
institution?

The results of the summary of the model to test the main hypothesis showed that the value of the correlation coefficient between the independent variable (human competency practices) and the dependent variable (institutional excellence) together amounted to (.749), which indicates the existence of a medium positive correlation between the variables, and the table also shows that The value of the coefficient of determination (R2) (.561), meaning that the model explained the proportion of $(56.1 \%)$ of the total variance of the dependent variable (institutional excellence), while the rest is explained by other factors.

The results of regression variance analysis of the impact of human competency practices on excellence in service provision, where the table shows the calculated $F$ value, which indicates the appropriateness of the model for regression testing, and that the relationship between the independent and dependent variables

Follow the linear model, where it reached $(66,972)$ at the significance level $(.000)$, and the decision rule states that the model is considered appropriate if the value of the significance level of (sig) is less than (0.05), and depending on the results obtained, the null hypothesis is rejected and the hypothesis accepted The alternative, which states (there is a statistically significant effect at the level $(\alpha \leq 0.05)$ of human competencies with its dimensions (efficiency, knowledge, good behavior, skills) in the service excellence provided in the Social Security Institution.

\section{Recommendations}

Based on the results of the analysis of the hypotheses of the study, the researchers found the following in this study:

1-It is necessary that one of the organization's strategic goals should be concerned with adopting, encouraging and maintaining the competencies of its employees for the purpose of achieving institutional excellence.

2-Holding more specialized training courses, which in turn increase the knowledge, skills and competencies of the employees and raise the level of their loyalty to the institution, which raises the level of performance and achieves excellence.

3-Improvement in work mechanisms, service delivery and the work environment of the institution, which increases its process of excellence.

4-The study recommends researchers to conduct more studies on the dependent variable "institutional excellence" by selecting other variables and dimensions and applying the study to other institutions.

\section{Conclusion}

Based on the results shown by this study, which we explained above in our discussion of the results "paragraph No.5.1.", all of which emphasized the correlation and the positive impact of the practices of maintaining human competencies and their dimensions selected in this study, and their impact on achieving institutional excellence and its dimensions also, in the Public Institution for Social Security - Jordan. And in refering to recommendationes mentioned above "paragraph No.5.2." which also based on the results, problem of the study, and analysis of the hypotheses of the study, researchers can state that achieving excellence by governmental organizations could be achieved when these organizations apply recommedationes above.

Consequently, the researchers believe that this study will contribute to drawing the 
attention of service-providing institutions especially governmental organizations, to the importance of focusing on their practice to maintain human competencies and to enhance partnership with these human competencies when making decisions, setting plans, and achieving the goals they seek to achieve in order to achieve institutional excellence.

\section{References}

Abdul Farraj, A. (2016). Measuring the Impact of Standards of Excellence on Performance Results. Sudan.

Abu Naser, S. S., Al-Shobaki, M. J., Amuna, Y. M. A., \& El-Talla, S. A. (2017). The Reality of Electronic Human Resources Management in Palestinian Universities from the Perspective of the Staff in IT Centers, 1, 74-96.

Adwan, M. (2011). The Reality of the Selection \& Appointment Policy \& its Impact on the Career Path of Employees in Banks Operating in the Gaza Strip. Gaza.

Ahmad, A., \& Al-Karkam, A. (2016). Application of Institutional Excellence to Upgrade Performance in Justice Institutions. Khartoum: Om Durman University.

Al-Aina, R., \& Atan, T. (2020). The Impact of Implementing Talent Management Practices on Sustainable Organizational Performance, 12.

Al-Ameen, M. (2016). Valuing professional experience gains, 6.

A'leqi, M. (2015). Human Resources Management, 5, 65.

Al-Haj Hasan, A. (2013). Human Resource Management Practices \& Their Impact on Achieving Institutional Excellence in the Kuwaiti Zain Company for Governmental Communications According to the Leadership Excellence Model. Jordan: MEU.

Al-Hila, A. A., Al-Shobaki, M. J., Abu Naser, S. S., \& Abu Amuna, Y. M. (2017). Proposed Model for Learning Organization as an Entry to Organizational Excellence from the Standpoint of Teaching Staff in Palestinian Higher Educational Institutions in Gaza Strip, 6, 39-66. Palestine, Gaza.

Ali, S. (2016). The Impact of Human Resources Management Policies in Achieving Job Satisfaction on Increased Production. Sudan: RSU.

Al-Omami, G. (2014). The Impact of Human Capital on Organizational Excellence in the Oil Sector in Libya. Egypt: Ain Shams University.

Al-Qaouri, A. (2012). The Impact of the Effectiveness of Human Resource Planning on Institutional Performance Excellence. Jordan: MEU.

Al-Qateef, A. (2014). The Integration of Human Resource Management \& Operations Management Practices, \& its Impact on the Productivity of Jordanian Industrial Companies \& their Lives. Lebanon: Jannat University.

Al-Ramadi, A. (2018). Institutional Excellence \& Development of NGOs Programs A Study from the Perspective of Community Organization Method, 13, 11.

Al-Teet, A. (2014). Operations Management \& its Impact on Corporate Productivity. Amman: PhD Thesis.

Auranzeb, B., \& Bhutto, S. (2016). Influence of Talent Management in Enhancing Organization Performance, 6, 49-55.

Balat, Y. (2015). The Relationship between External Sources of Employment \& Organizational Performance, 24, 125-149.

Bernathalse, R. (2016). Better Recruitment \& Selection Strategic Result in Improved Organizational Outcomes, 1, 23.

Bu-Tayyeb, A., \& Meqdad, A. (2016). The role of managing human competencies in achieving competitive advantage, a case study of the "Milk of Success" Foundation. Algeria. 
Faraj-Allah, A. (2017). The Role of Strategic Orientation in Explaining the Relationship Between the Availability of Process Re-Engineering Entrance Requirements \& Operational Performance, 4, 442-446. Sudan.

Harrungton, J. (2008). The Impossible Dream, 1, 74-96. Riyadh: King Adbulaziz Quality Award. Hasan, H. (2009). Human Resources Employment Strategy \& its Impact on Achieving Competitive Advantage: An Applied Study in the Jordanian Telecom Sector. Jordan: MEU.

Hijazy, N. (2016). Employment \& its Relationship to Institutional Excellence. Palestine, Gaza: Al-Azhar University.

Hussein, R., \& Sultan, M. (2014). Human Resources Management. Egypt: Dar Al-Ta'leem AlJame'e.

Jabbouri, N., \& Zahari, I. (2014). The Role of Core Comperencies on Organizational Performance.

Khalaf, M. (2015). Strategic Planning \& its Impact on the Performance of Human Resources for the Oil Sector. Morocco: University of Ribat.

Khedri, T. (2019). The Effect of Material Incentives on the Performance of Competencies, a Case Study of the Ain Touta Cement Company "Batnah". Algeria.

Lyria, R. K. (2014). Effect of Talent Management on Organizational Performance in Companies Listed in Nairobi Securities Exchange in Kenya. Japan, Harumicho: University of Agriculture \& Technology.

Mahmood, M., Awais, M., Afzal, M., Shahzadi, I., \& Khalid, U. (2017). The Impact of Human Resource Management Practices on Organizational Performance, 1, 165-178.

Mahmoud, M. (2014). Studies \& field applications in the fields of social work, 1, 197. Egypt, Alexandria: Modern University.

Mohammad, A. (2015). Intellectual Capital \& its Impact on Achieving Institutional Excellence. Sudan: University of Sudan.

Mohammad, A. (2015). The Impact of Human Resources Management on Achieving Institutional Excellence, 1, 1. Sudan: RSU.

Mohammad, M. (2017). The Impact of Strategic Planning on the Performance of Human Resources in the Heavy Industry Sector. Sudan.

Olwan, A., Irtaimeh, H., \& Al-Lozi, M. (2019). Strategic Leadership Competencies \& its Impact on Achieving Organizational Excellence via the Mediating Role of Organizational Commitment, 8.

Oqaily, O. (2015). Contemporary Human Resources Management, a strategic dimension, 1, 1.

Pinar, T. M., \& Girard, A. (2008). Organizational learning \& the learning organization review. Evolution for prospective the future the learning organization, 15, 294-308.

Qalbo, H. (2016). The Role of Knowledge Management in Improving Institutional Performance, 1, 42. Algeria: University of Mohamed Khider.

Salami, F. (2017). The Role of Competency Management in Achieving the Competitive Advantage of the Institution. Algeria.

Saleem, N. (2020). Human Resource Management Practices \& their Impact on Achieving Organizational Excellence, 2. Egypt, Giza: Oct. $6^{\text {th }}$ University.

Seqaran, U. (2013). Research Methods in Management: An Introduction to Building Research Skills. Riyadh: KSU.

SSC, H. (2020). SSC. Jordan.

Tahani, H. (2015). Strategic Orientation \& its Impact on Corporate Performance: Knowledge Management as an Intermediary Variable. Sudan: University of Sudan. 
Taie, E. S. (2015). Talent Management is the Future Challenge for Healthcare Managers for Organizational Success, 1, 18-27.

Taresh, A. (2016). A Strategic Vision to Achieve Information Security in the Investigation \& Public Prosecution Authority in the Kingdom of Saudi Arabia. Riyadh: NAU.

Vrchota, J., Pech, M., Rolínek, L., \& Bedná r, J. (2020). Sustainability Outcomes of Green Processes in Relation to Industry 4.0 in Manufacturing, 12, 59-68. 